\title{
A dimensão social do conhecimento
}

\author{
Emir José Suaiden
}

Instituto Brasileiro de Informação em Ciência e Tecnologia (Brasil)

\section{Resumen}

El conocimiento y la información han pasado a cobrar nueva importancia en el contexto de la sociedad de la información. Cuando pensamos hoy en ambos valores, es preciso mirarlos bajo la óptica de la educación, la economía y la cultura, pues el proceso de información es global y abarca a todos los países directa o indirectamente con mayor o menor intensidad. Así, los países de la América Latina tienen que utilizar adecuadamente la transferencia de la información para resolver los grandes problemas como el analfabetismo, la exclusión digital y la falta de una industria de contenidos. La resolución de esos problemas es determinante para el crecimiento de la producción científica y para la producción de patentes, además de mejorar la calidad de vida de las poblaciones.

Palabras clave: Sociedad de la información. Políticas para el desarrollo. Alfabetización digital. Alfabetización informacional. América Latina.

\section{Abstract}

Knowledge and information have new importance in the context of the information society. Today, when we think of both values it is necessary to look at them under the educational, economical and cultural perspectives because the information process is global and has to do with every country directly or indirectly in a greater or a lesser extent. Therefore, Latin American countries must use infomation transfer in order to solve great problems such as illiteracy, digital exclusion and the lack of a contents industry. The solution to these problems will determine the growth of the scientific production and improve the quality of life of the populations.

Keywords: Information society. Development policies. Digital literacy. Information literacy. Latin America.

\section{Introdução}

Em cada período histórico as sociedades humanas têm elementos que caracterizam a base de sua organização social. Quando esses elementos se convertem em princípios de ação, ou em princípios organizadores do comportamento humano 
e da forma como as organizações e as instituições sociais funcionam, eles se constituem em valores que caracterizam o seu entorno social e o período histórico que estão construindo. Criado pela necessidade que tem o homem de entender e explicar o meio em que vive, esse é o papel que a informação e o conhecimento desempenham no mundo hoje.

As sociedades que conseguem, através de processos contínuos de geração e uso do conhecimento, organizar-se de tal forma que possam contribuir para o processo de aprendizagem social, são classificadas como sociedades do conhecimento. Estas são sociedades com capacidade para gerar conhecimento sobre sua realidade e seu entorno, e em condições de utilizá-lo em seu processo de conceber e construir seu futuro. Desta forma o conhecimento se transforma não só em instrumento para explicar e compreender a realidade, mas também em motor de desenvolvimento e fator dinamizador das mudanças sociais.

Vinte e um é o século da tecnologia e da informação, época em que o conhecimento é o elemento central da estrutura econômica que está surgindo, e a inovação o principal veículo de transformação do conhecimento em valor. A produção de conhecimento e sua incorporação em inovações tecnológicas são instrumentos cruciais para o desenvolvimento sustentável de qualquer nação. É fácil constatar que o movimento transformador, o qual atualmente atinge a informação, a comunicação e a própria educação, constitui uma profunda revolução tecnológica. Para isso basta lembrar o fato de um estudo da União Européia, publicado no informativo, publicado em Bruxelas (A sociedade da informação, de 1996), dizer que nos últimos vinte anos dobraram os nossos conhecimentos científicos, os quais correspondem, hoje, à totalidade de conhecimentos técnicos acumulados durante toda a história da humanidade.

Vivemos em um mundo interconectado, em que as proporções dos sistemas globalizados de comunicação superaram os prognósticos mais otimistas. Por exemplo, quando Arthur Clarke teve a idéia de satélites estacionários, em 1945, acreditava não ser possível desenvolvê-los antes do ano 2000. Entretanto, bastaram duas décadas para que se pusesse em órbita o Early Bird, logo denominado Intelsat I. De modo que quando Neil Armstrong desceu na lua, em um outro cenário de ficção, quase todo mundo pode vê-lo pisando em um terreno, em que antes só era possível caminhar nas fantasias de escritores e de artistas de há muitos séculos.

Esse foi o início das comunicações globalizadas, as quais estão transformando a civilização contemporânea. A decantada Internet, rede mundial de computadores, é o centro de uma revolução que está afetando profundamente nossos modos de comunicação, de aprendizado, de trabalho e de governo. Por outro lado estão avançando as aplicações que tornam realidade as reflexões de visionários como R. Buckminster Fuller e J. C. R. Licklider, que, há algumas décadas, teorizam sobre a possibilidade de desenvolver sistemas automáticos de interação com o conhecimento. 
Castells (1994, p. 25) faz referência a um processo de transformação estrutural das sociedades avançadas, vinculado à revolução tecnológica, à globalização econômica e cultural e à habilidade de gerar conhecimento e de processar informação. A idéia é que a produtividade e o crescimento econômico, assim como a geração de riquezas e de poder, estruturam-se socialmente sobre o controle do conhecimento e da informação.

\section{Informação e conhecimento na América Latina do século XXI}

O conhecimento e a informação passam a ter nova importância nesse contexto. A revolução tecnológica, característica primeira do novo milênio, transformou a realidade, modificou valores, que caracterizaram as ultimas décadas do século XX, extinguiu profissões, criou outras e tornou imperativo uma nova forma de organização. Deixou claro que precisamos rever nossos conceitos e acima de tudo, conceituar de uma maneira nova, antigos valores.

Quando se pensa em informação e conhecimento na atualidade, é necessário conceituar esses valores sob a ótica da educação, da economia e da cultura. É fundamental identificar a dimensão humana, onde a educação é o cerne da questão; a dimensão tecnológica, onde o fator econômico tem fundamental importância e; a dimensão social, onde a cultura se apresenta como resultado das transformações ocorridas na sociedade.

O processo de transformação é global, atinge a todos os países direta ou indiretamente, mais ou menos intensamente. Nos países desenvolvidos a sociedade do conhecimento surge como conseqüência natural do processo de desenvolvimento.

Na América Latina, em especial no Mercosul, assim como em todos os países em desenvolvimento, é necessária a adoção de estratégias políticas, educacionais e sociais traduzidas em forma de programas e ações que possibilitem a inclusão destas sociedades no mundo globalizado.

A implantação da sociedade da informação no Mercosul é um tema atual e cada vez mais discutido nas estruturas governamentais e nos eventos científicos. A pergunta mais discutida é a seguinte: é possível estabelecer em médio prazo a sociedade da informação na região? Para responder a essa pergunta é de suma importância analisar as estruturas educacional, econômica e social do Mercosul e ao mesmo tempo compará-las com as exigências da própria sociedade da informação.

A sociedade da informação traz no seu bojo os mesmos indicadores das sociedades anteriores, tais como, poder aquisitivo, nível educacional e linguagem, o seu diferencial é a necessidade de acesso à informação, seja bibliográfica ou virtual. Quando se analisam as estruturas informacionais verifica-se que elas são deficientes porque, com exceção de Brasil e Argentina, não existe uma indústria editorial forte e 
conseqüentemente um público leitor adequado o que torna deficiente a formação de conteúdos para a sociedade da informação. Quando um país em desenvolvimento importa muitos conteúdos, por não tê-los, é um indicador que ele é dependente e continuará a ser dominado. Não terá uma produção cientifica e tecnológica adequadas ao processo de desenvolvimento, até que essa realidade seja transformada.

\section{Educação e desenvolvimento na América Latina}

A estrutura educacional e social em geral, existente na América Latina e no Mercosul, ainda é muito precária e contribui para o alto índice de analfabetismo, desnutrição infantil e desemprego da região. Em muitas localidades a grande motivação para o aluno freqüentar a escola é a merenda escolar e não o sistema educacional. São poucas as escolas com bibliotecas e em algumas delas ainda se encontra o professor leigo. Quando há biblioteca o acervo geralmente é composto de livros didáticos e de referência, são poucos os títulos representativos de literatura infantil e juvenil.

A pesquisa é sempre o lado mais abandonado do sistema educacional, pois na prática ela se baseia na cópia de dicionários e enciclopédias. Quando existe computador a pesquisa é realizada copiando textos da Internet. Os conteúdos programáticos dos cursos são baseados muitas vezes em apostilas e livros desatualizados. Os professores geralmente são mal remunerados e com baixa estima o que acaba sendo transferido para os alunos. O que se observa é o compartilhamento do despreparo, da desinformação, da dependência.

Geralmente não existe coordenação pedagógica, há falta de planejamento e dialogo entre os professores o que inviabiliza a questão da interdisciplinaridade. A formação dos professores é precária, geralmente não há programas de capacitação adequados. Nos últimos anos a violência tem crescido assustadoramente nas escolas, já há registro de alunos armados no recinto escolar e agressão aos professores. Os alunos com melhor poder aquisitivo abandonam a escola pública e passam a utilizar a escola privada.

Os indicadores do fracasso escolar são a falta de capacitação do professor, pois em algumas regiões os professores são leigos; a falta de infra-estrutura de laboratório, biblioteca escolar e; conteúdos didáticos inadequados para a região. Esses problemas acabam afetando o aprendizado do aluno que muitas vezes não consegue interpretar um texto mínimo e se organizar intelectualmente para entender matemática e física, por exemplo. Esta cultura da desinformação, da manipulação e da dependência possibilita a concentração de renda, a desigualdade social e a exclusão.

Numa rápida análise sobre a dimensão econômica do Mercosul foi possível verificar que tem aumentado, especialmente nos últimos anos, a desigualdade, pois a riqueza é concentrada numa minoria da população. Estudos recentes comprovam 
que parte expressiva da população que pertencia à classe média hoje faz parte da classe pobre, pois há um declínio cada vez maior das classes sociais. O alto índice de desemprego estimula o mercado informal onde muitas vezes a mercadoria dominante é a pirataria com total desrespeito à produção intelectual e à falta de ética relacionada com os direitos autorais. Realidade estabelecida pela necessidade de sobrevivência e a única forma de acesso a bens culturais para muitos.

$\mathrm{Na}$ verdade a informação ainda não é visível para grande parte da população dos países em desenvolvimento. Muitas gerações se formaram sem ter a compreensão do que significam acesso à escola, bibliotecas escolares, bibliotecas públicas, bibliotecas infanto-juvenis, teatro, cinema e lazer. Essas instituições foram vistas como instituições de elite e adequadas para uma cultura erudita. No entanto, a biblioteca pode transformar a qualidade de vida das comunidades disseminando informação adequada com a rapidez que os tempos modernos exige. Esse trabalho deve partir de um diagnóstico bem elaborado sobre as necessidades informacionais da comunidade para em seguida, com o auxílio de técnicas de tomada de decisão, elaborar um planejamento estratégico compatível com a realidade local.

Como não conseguimos desenvolver uma cultura bibliográfica, ainda hoje a informação que circula, nesses países, é a informação oral que é obtida informalmente na igreja, no trabalho, nos meios de comunicação e na escola. Tanta informalidade leva o indivíduo a se acostumar também com a educação informal e posteriormente com o trabalho informal que são temas totalmente incompatíveis com a filosofia da sociedade do conhecimento. Na medida em que não existe na região uma política de informação que privilegie a inclusão social, esse papel terá que ser realizado pelo profissional da informação que deverá trabalhar como mediador para possibilitar o compartilhamento do conhecimento.

\section{Dimensão social do conhecimento}

Quando falamos de dimensão social do conhecimento estamos identificando um nível de consciência coletiva que exige a melhor distribuição dos saberes e das riquezas geradas pela sociedade. É uma sinalização para a necessidade de diminuir as desigualdades e socializar o bem estar, a qualidade de vida, a cidadania e a dignidade humana. Nesse sentido é necessária uma grande mobilização da sociedade onde cada órgão, instituição, empresa e indivíduo trabalhem pela equidade social. Dessa forma é possível pensar na construção de uma nova mentalidade que resultará na formação de uma cultura que represente uma sociedade mais justa, baseada na tecnologia, na informação e no conhecimento, solidários.

Aprofundando um pouco mais a discussão a respeito da dimensão social do conhecimento, a cultura que se forma a partir da revolução tecnológica impõe uma maior responsabilidade social ao governo, às empresas e aos indivíduos partícipes da sociedade globalizada.

Scire. $13: 1$ (en.-jun. 2007) 21-31. ISSN 1135-3716. 
Para deixar mais claro o conceito de dimensão social do conhecimento vamos analisá-lo sob o ponto de vista prático. Como ele se apresenta na educação, no mercado e no governo.

$\mathrm{Na}$ educação, por meio dos projetos de inclusão digital desenvolvidos nas escolas, bibliotecas ou em qualquer ação educacional. Nesse caso é fundamental que o educador tenha clara a sua função de mediador para que os ensinamentos oferecidos possam ir além dos conteúdos programáticos oferecidos pelos governos competentes. É indispensável mostrar aos educandos seu papel no contexto em que vivem enquanto atores sociais do momento histórico que sua geração esta construindo. A dimensão social do conhecimento no âmbito da educação seja ela formal ou não, é insumo e produto da capacidade crítica, competência, comprometimento e compartilhamento dos educadores e dos educandos.

A biblioteca deveria ser o grande instrumento da educação especialmente no que diz respeito à dimensão social do conhecimento. Tradicionalmente as bibliotecas são criadas por decretos e absolutamente desassociadas da realidade da comunidade onde estão inseridas, elas não são visíveis para aqueles cidadãos. Alem da invisibilidade, não provocam nenhum impacto social nas organizações que teoricamente teriam que atuar como propagadores e multiplicadores de uma política educacional, cultural e social como o sistema educacional, a maior prova disso é a constante falta de orçamento nas atividades de disseminação da informação.

No âmbito do mercado é possível se perceber uma movimentação no sentido de tornar visível a dimensão social do conhecimento. As empresas estão se manifestando em relação a essa questão por meio da responsabilidade social que está cada vez mais presente no marketing institucional e nos investimentos em projetos que visam a melhoria da qualidade de vida das comunidades menos favorecidas. São muitos os projetos de inclusão social e digital patrocinados pela iniciativa privada, por exemplo. Outro indicador que ratifica essa afirmação é uma maior aproximação entre a academia e as empresas, no sentido de desenvolver pesquisas que agreguem valor aos seus produtos, de maneira a atender melhor as demandas da sociedade. Essa nova postura do mercado é provocada pela dimensão social do conhecimento e uma sinalização de que estamos, no caso brasileiro, caminhando em direção à sociedade da informação.

No que diz respeito a sociedade essa dimensão social do conhecimento se materializa por meio das Organizações Não Governamentais (ONGs), as Organizações da Sociedade Civil de Interesse Público (OSCIPs), das associações e cooperativas que têm crescido muito nos últimos anos. Essas instituições estão focadas na dimensão social do conhecimento na medida em que seus trabalhos se desenvolvem, de modo geral, a partir do compartilhamento do conhecimento, experiências e saberes na busca da melhoria da qualidade de vida da comunidade onde atuam. É possível observar que o conceito de parceria e seu efetivo exercício 
foram incrementados e popularizados a partir dessas organizações. O conceito que norteia as empresas sem fins lucrativos é o desenvolvimento sustentável, a qualificação profissional, emprego e renda, educação, ecologia, enfim, todos itens voltados para a melhoria da qualidade de vida na busca da equidade social.

Na esfera governamental a dimensão social do conhecimento é visível por meio de ações que levam a inclusão social, apoio a projetos que contribuam para melhorar a qualificação do cidadão diminuindo as desigualdades sociais, e o e-gov disponibilizando, via web, os serviços públicos sejam federais, estaduais ou municipais, de maneira prática, com baixo custo e de forma democrática.

Essas ações deixam claro que a dimensão social do conhecimento, ou seja, a sua apropriação pela sociedade e seu reflexo na formação da cultura social contemporânea, está presente no planejamento e ações governamentais.

\section{Informação, conhecimento e exlusão}

$\mathrm{Na}$ complexidade da sociedade em que vivemos ou tentamos viver, a da informação e do conhecimento, surgem novos valores que passam a caracterizála. A inovação é um valor fundamental dessa nova sociedade e a criatividade a inquietação primeira, para romper as barreiras que protegem a ordem estabelecida e impõe mudanças, sejam elas social, tecnológica ou cultural.

A revolução tecnológica assinala um novo marco na história do desenvolvimento. Ela colabora para romper uma série de paradigmas e traz em seu bojo as questões fundamentais da mudança e inovação.

A questão da mudança esta muito relacionada com os novos valores da sociedade do conhecimento e as pessoas que não estão preparadas para enfrentálas, passam automaticamente a alimentar o percentual de excluídos. Só é possível mudar com consciência crítica, própria das pessoas com hábito de leitura e de utilização da informação, o que requer um bom nível educacional.

As organizações têm que mudar para se tornarem mais competitivas e só conseguem se agregarem um valor chamado inovação. A inovação produz novos nichos de mercado e fortalece a construção da sociedade do conhecimento. Mudança e inovação conduzem à geração de emprego e renda, mas contribuem para a ampliação do mapa da exclusão na medida em que novas profissões surgem outras desaparecem e a exigência de maior qualificação é uma constante em todos os setores.

O cidadão excluído da sociedade da informação é uma pessoa com baixa estima, de olhar cabisbaixo, pouco criativo e extremamente dependente. Ele não tem noção de cidadania e geralmente é explorado pela hegemonia reinante. A sua comunidade é dominada pela desinformação, ou seja, a informação é manipulada e ele não tem capacidade crítica para tomar decisão.

Scire. $13: 1$ (en.-jun. 2007) 21-31. ISSN 1135-3716. 
Para combater esse processo de desinformação e manipulação da informação, a revolução tecnológica pode ser uma grande aliada. O que ocorre nos países em desenvolvimento é que um grande percentual da população não tem acesso à tecnologia, nunca viu um computador. Para essas pessoas o acesso e a compreensão devem ser realizados por meio de metodologias adequadas de mediação da informação que se inicia pela alfabetização da informação. Nesse processo de inclusão a dimensão social do conhecimento é o foco que não pode ser perdido.

Os índices de violência e falta de segurança em países pobres são cada vez maiores e refletem a desigualdade na região. As instituições que teoricamente deveriam facilitar o acesso à sociedade da informação como a biblioteca e o sistema educacional, por uma série de fatores não conseguem atingir o referido objetivo. Nessa estrutura o papel do profissional da informação passa a ser de extraordinária importância, desde que se corrijam alguns vícios existentes na própria formação educacional. Até hoje a maioria das escolas de Biblioteconomia e Ciência da Informação existentes na região não privilegiam nem a mediação da informação nem a formação de um profissional que seja um propagador de uma política de leitura e utilização da informação.

\section{A dimensão humana da informação: uma linha de pesquisa}

Para romper as barreiras acima apontadas foi criada uma linha de pesquisa denominada dimensão humana da informação. Esse fato é importante por ratificar as colocações anteriores sobre a dimensão social do conhecimento. É representativo das mudanças que necessitam acontecer para que se possa construir, com mais competência e rapidez, a ponte de acesso ao conhecimento que possibilita a travessia do fosso existente entre os países desenvolvidos e aqueles excluídos da Sociedade da Informação.

Durante mais de uma década e contando com o apoio do Conselho Nacional de Desenvolvimento Científico e Tecnológico (CNPq), foram realizadas investigações sobre o comportamento de populações marginalizadas em relação ao acesso ao livro, a biblioteca e a informação.

Foram iniciadas nos anos noventa pesquisas com metodologias adequadas para comprovar, principalmente, que para as populações marginalizadas o acesso à informação não é tão importante quanto a sua compreensão. Para ilustrar podemos citar o exemplo de moradores de rua, que vivem na Praça da Sé em São Paulo. A informação esta disponível para todos na Biblioteca Pública Mario de Andrade, bem próximo daquele local. A possibilidade do acesso é real, mas a falta de compreensão do seu significado a torna invisível.

Grande parte das pesquisas desenvolvidas foi realizada em escolas públicas e foi constatado que biblioteca e informação não são prioridades para o sistema 
educacional. Os diretores das unidades de ensino tiveram dificuldade em perceber que o fracasso escolar - representado pela evasão, repetência e formação educacional inadequada- é o maior indicador da falta de disseminação adequada da informação.

O uso indiscriminado do livro didático formou uma geração que não sabe interpretar o texto lido. Foi observado que a pesquisa escolar ficou restrita a cópia de dicionários e enciclopédias; que a literatura infantil e juvenil não é estimulada como deveria quando se sabe que o interesse do estudante por esse tipo de leitura deve ser despertado pelo professor e pelo bibliotecário. Programas como "A hora do conto", por exemplo, onde o especialista em leitura promove a motivação necessária para a iniciação à literatura, são fundamentais para a formação de um leitor crítico. Nas avaliações dos projetos foi possível constatar que esse tipo de acesso à biblioteca é de fundamental importância para a formação de um público leitor e conseqüentemente um caminho viável de inclusão na Sociedade da Informação. Os projetos mencionados foram desenvolvidos em cidades satélites de Brasília, em regiões carentes do Distrito Federal.

A partir dos resultados obtidos nas pesquisas colocadas anteriormente e sob a perspectiva da utilização de recursos tecnológicos, computadores e softwares adequados, o trabalho foi ampliado e foi agregado um novo elemento à inclusão social por meio da leitura, a inclusão digital. A técnica da mediação foi agregada à metodologia etnográfica na construção de um modelo de inclusão que viesse ao encontro das necessidades do cidadão excluído, adequado a realidade brasileira. Dessa forma trabalhou-se no sentido de consolidar um modelo de inclusão social, a partir de uma ação de inclusão tecnológica, baseado na mediação da informação, mediação essa, aqui compreendida em sua relação mais estreita com a disseminação, transferência e transformação da informação em conhecimento.

Compõe o modelo a criação de um sistema de indicadores que possibilite a medição dos impactos sociais provocados pelas novas tecnologias tanto no processo ensino/aprendizagem como na formação do cidadão e da comunidade. Assim como acompanhamento e avaliação de seus resultados em um período mínimo de doze meses. Outro ponto importante foi identificar na atuação do profissional da informação que atende a escola, especialmente o bibliotecário e do monitor que atende a comunidade, quais os momentos e em que medida a mediação da informação se faz presente e é determinante daquela atividade. Esse modelo se concretizou na Escola Digital Integrada (EDI) e no conceito dos Centos de Integração Social e Tecnológica (Cistec).

\section{Conclusão}

Ao longo da historia da humanidade o homem vem incorporando os novos inventos para melhorar sua qualidade de vida. Lamentavelmente estes avanços não

Scire. $13: 1$ (en.-jun. 2007) 21-31. ISSN 1135-3716. 
têm chegado de igual modo a todas as pessoas. As desigualdades e injustiças sociais têm sido e são uma constante na história do gênero humano.

O conceito de Terceiro Mundo surgiu para referir-se ao mundo subdesenvolvido em contraposição as sociedades mais ricas, que formariam o Primeiro Mundo. O Segundo Mundo seria formado pelos países do bloco de economia socialista estatal. Hoje já começa a surgir a idéia de Quarto Mundo, composto pelas manchas negras da exclusão existente em todo o planeta, presente em cada país e em cada cidade, nesta nova geografia da exclusão social.

As pesquisas mencionadas consolidaram a compreensão de que em um modelo de desenvolvimento marcado pelas desigualdades, fica claro que a revolução tecnológica poderá agravar ainda mais a exclusão social se não for adequadamente conduzida. Enviar computadores para as populações marginalizadas, sem uma proposta adequada de mediação da informação, com certeza não contribuirá efetivamente para a inclusão de cidadãos na sociedade da informação.

Essa breve retrospectiva evidencia a dimensão social do conhecimento que se traduz pela integração da sua dimensão humana e tecnológica, com o objetivo de contribuir para o desenvolvimento social de toda a nação. Quando uma sociedade não tem espírito crítico para se rebelar contra a falta de políticas e estruturas informacionais, só resta o apoio decisivo dos profissionais da informação para mudar a situação existente.

O trabalho com comunidades marginalizadas exige muito esforço, compreensão, liderança e a utilização de metodologias adequadas. O empresário, o acadêmico, o cidadão incluído na sociedade da informação, deve encarar esse tipo de trabalho como um desafio e principalmente como um resgate da sua divida social. A falta de leitores, de cidadãos críticos, segundo os sociólogos, ocorre pelo fato de termos passado rapidamente de uma cultura oral para uma cultura audiovisual, o que enfatiza a necessidade do mediador no processo de inclusão.

No Brasil, não obstante os enormes avanços econômicos ocorridos, o país deixou de realizar reformas e tomar decisões políticas, que impossibilitaram o enfrentamento dos problemas associados à concentração de riqueza e à exclusão social. Em função disso, a manipulação de critérios simplistas como estar ou não alimentado, ser ou não alfabetizado, ter ou não ocupação com rendimento adequado, passou a se mostrar insuficiente para dar conta do processo de exclusão. Também se tornou inadequada apenas a indicação quantitativa de acesso à educação, trabalho, informação, entre outros, necessitando acoplar a noção de qualidade do acesso aos bens e serviços públicos.

O conceito de exclusão social vem sendo adotado, de forma crescente, para dar conta de um fenômeno que se manifesta de maneira cada vez mais complexa. Nos horizontes que se anunciam, não se aceita mais a exclusão nem o mero contentar-

Scire. $13: 1$ (en.-jun. 2007) 21-31. ISSN 1135-3716. 
se com a miséria. Inserir os excluídos é a semântica da solidariedade. No entanto, as atividades anti-solidárias ainda encontram eco e condições favoráveis à sua proliferação. Remam contra essa corrente as apostas no atual desenvolvimento tecnológico e nas redes interativas que o acompanham, multiplicando-as em redes de solidariedade.

A dimensão social do conhecimento tem um papel central nesse processo. Ela representa a aliança entre a academia, o governo, a iniciativa privada e a sociedade civil organizada. O papel da academia é fomentar a pesquisa, criar fundamentação teórica, desenvolver metodologias adequadas e produzir conhecimentos que contribuam para a solução dos problemas nacionais. O papel do Governo é formular políticas públicas, criar infra-estrutura para favorecer a inclusão social e a disseminação do conhecimento. O papel da iniciativa privada é o resgate da sua responsabilidade social. O papel do Terceiro Setor é facilitar as ações de todos os atores anteriormente citados. Essa é a única aliança possível capaz de gerar sinergia suficiente para implementar uma política de justiça social, criar uma consciência solidária para minimizar as desigualdades e ampliar a sociedade da informação no Brasil.

\section{Referências}

Castells, Manuel (1994). Flujos, redes e identidades: uma teoria crítica de la sociedad informacional. // Nuevas perspectivas críticas en educación. Actas del congreso internacional. Barcelona: Paidós, 1994. 13-54.

Castells, Manuel (1997). The power of identity: the information age: economy, society and culture. Vol. 2. Oxford: Blackwell, 1997.

Eigen, Manfred (1997). O que restará da biologia do século XX? // Michel P. Murphy e Lucke J.O'Neil (orgs.). O que é vida? 50 anos depois: especulações sobre o futuro da Biologia. São Paulo: Unesp, 1997. 13-33.

Lévy, Pierre; Authier, Michel (1998). A inteligência coletiva: por uma antropologia do ciberespaço. São Paulo: Loyola, 1998.

Oliveira, Cecília Leite (1996). Biblioteca pública, centro convergente das aspirações comunitárias: serviço de informação à comunidade nas bibliotecas públicas do Distrito Federal. Dissertação de mestrado. Brasília: Universidade, 1996.

Oliveira, Cecília Leite (2002). A revolução tecnológica e a dimensão humana da informação: a construção de um modelo de mediação. Tese de doutorado. Brasília: Universidade, 2002.

Suaiden, Emir (2000). A biblioteca pública no contexto da sociedade da informação. // Ciência da informação. 20:2 (2000) 52-60.

Suaiden, Emir (2003a). El impacto social de la lectura. // De antologia. 2 (2003) 81-90.

Suaiden, Emir (2003b). The social impact of public libraries. // Library Review. 52:8 (2003) 379-387.

Tarapanoff, Kira; Suaiden, Emir; Oliveira, Cecilia Leite. Funções sociais e oportunidades para profissionais da informação. // DataGramaZero. 3:5 (2002). http://www.datagramazero. org.br/out02/F_I_art.htm (2007-03-20).

Scire. $13: 1$ (en.-jun. 2007) 21-31. ISSN 1135-3716. 